2. Порядок открытия иностранного представительства и условия его деятельности должны быть четко определены в законодательном порядке, то есть действующее до сих пор законодательство Союза ССР должно быть заменено новым, отвечающим потребностям настоящего времени. Во вновь принимаемых актах необходимо учесть положения новейшего российского законодательства, что позволит избежать различных толкований и проблем в осуществлении контроля за деятельностью иностранных юридических лиц на территории Российской Федерации.

1 СМ. Комоевтарй к ГК РСФСР/Под ред. Е.А. Флейшиц и О.С. Йоффе. М., 1970. - С. 57 и сл.

2 Ратифицировано 18 апреля 1989 г.

3 Ведомостн СНД СССР в ВСС. -27 февраля 1991 г. - No 9. - Ст. 208. (В настоящее время ратифицированные СССР международные договоры в силу правопреемства действуют на территории РФ.)

4 См. раздел XXI Постановления Совета Мпвнстров РСФСР or 25 декабря 1990 r., 10601.

\title{
К ВОПРОСУ О ПРАВОВОМ ПОЛОЖЕНИИ ИНОСТРАННЫХ ПРЕДСТАВИТЕЛЬСТВ В РОССИИ
}

\section{А.А. Кислицын *}

Речь пойдет о представительствах иностранных фирм, банков и организаций, ведуших коммерческую деятельность. С самого начала важно отметить, что, согласно новой Конституции РФ, внешнеэкономическая деятельность (а значит, и регулирование порядка открытия и деятельности представительств) находится исключительно в ведении федеральных органов. Растущая деловая активность иностранных фирм требует открытия таких представительств, и практика уже сложилась, несмотря на пробелы законодательства в этой сфере.

Центр деловой активности в Российской Федерации - это, безусловно, Москва, и мы попытаемся ответить на этот вопрос не теоретически, а используя спешиально собранный материал и практический опыт работы фирмы Московский Бизнес-Сервис Центр ${ }^{\star \star}$.

Проблемы начинаются уже с определения самого термина. Что такое представительство иностранного юридического лица (ИЮЛ)?

* Адвокат Московского Бизнес-Сервис Центра.

** Фирма́ не претендует на то, что ее мнение по настоящему вопросу единственно верное. 
Согласно статье 24 действуюших до настоящего времени Основ гражданского законодательства Союза ССР и республик, "представительством является обособленное подразделение юридического лица, расположенное вне места его нахождения и осуществляющее зашиту и представительство интересов юридического лица, совершающее от его имени сделки и иные правовые действия". Представительства не являются юридическими лицами, наделяются имуществом создавшим их юридическим лицом и действуют на основанни утвержденного им положения.

На сегодняшний день действует около 20 законов, законодательных и нормативных актов, а также ведомственных инструкций, касающихся представительств иностранных юридических лиц. Однако приведенная формулировка - практически единственная, определяющая их юридический статус.

В функционировании представительства можно выделить:

1. Открытие.

2. Продление аккредитации и срока деятельности представительства.

3. Закрытие представительства.

4. Пробелы в законодательстве.

\section{1. ОТКРЫТИЕ ПРЕДСТАВИТЕЛЬСТВА}

Согласно действующему "Положению о порядке открытия и деятельности в СССР представительств иностранных фирм, банков и организаций”, утвержденному Постановлением СМ СССР от 30 ноября 1989 г. № 1074 (далее - Положение)," 9. Представительство инофирмы считается открытым В СССР с даты выдачи разрешения на его открытие", иными словами - с момента аккредитации. Фактически же это только первый этап. Сложившаяся практика и новое законодательство позволяют нам определить следующие действия как необходимые для открытия представительства:

- аккредттацпя;

- perистрания в местных органах властн;

- постановка на учет в Налоговой пспекциг;

- постановка на учет в Пенснонном фонде;

- постановка на учет в Фонде обязатељього меднинского страхования;

- открытие счета в банке. 


\section{Aксредитащия}

Аккредитоваться (получить особое разрешение на открытие) представительство иностранной фирмы может в зависимости от характера (профиля) деятельности при десяти учреждениях и организациях (далее - аккредитуюшие органы).

Положение не раскрывает многие аспекты достаточно подробно, и это привело к тому, что в разных аккредитующих органах механизм аккредитаџии выглядит по-разному. Проиллюстрируем диапазон расхождений:

Срок аккредитации 1-3 года

Количество документов, необходимых

для аккредитации 4-12

Размер сбора за аккредитацию

$0-\$ 2000$

Срок вынесения решения об

аккредитации

Продление аккредитации на срок

7-60 дней

Размер сбора за продление

аккредитации

1-3 года

Максимально разрешенное

количество иностранных сотрудников

Форма оплаты

сбора за аккредитацию

$0-\$ 1000$

Каждый аккредитующий орган самостоятельно решает, соответствует ли характер деятельности иностранной фирмы профилю аккредитующего органа, а значит, может ли эта фирма быть аккредитована именно при этом ведомстве. Нередко фирмы теряют недели и месяцы в поисках организации, которая согласится их аккредитовать.

Относительно документов, которые необходимо представить в аккредитующий орган, в Положении говорится: "5. Инофирма, заинтересованная в открытии представительства, подает в соответствующий аккредитующий орган письменное заявление”. К заявлению, переведенному на русский язык, должны быть приложены следующие официальные документы:

- Устав фирмы.

- Выписка из торгового реестра.

- Особое разрешение на открытие представительства в РФ от государственных учреждений страны местонахождения инофирмы (в случае, если таковое требуется).

- Доверенность представителю инофирмы, ведущему от ее имени переговоры об открытии в РФ представительства.

- Копия платежного поручения от уплате сбора за выдачу 
разрешения на открытие представительства (если это требуется). По Положению, "инофирма до получения разрешения на открытие или продление срока деятельности в СССР своего представительства уплачивает сбор в соютветствии с законодателством СССР".

Все вышеперечисленные документы (кроме последнего) должны быть легализованы и переведены на русский язык. Как показывает практика, самый оперативный и одновременно экономичный вариант - это легализация всех документов в стране местонахождения инофирмы путем проставления Апостиля (в соответствии с Гаагской конвенцией от 5 октября 1961 г.), а затем перевод их на русский язык и, если понадобится, изготовление нотариальных копий в РФ.

Количество необходимых документов может быть и бо́льшим. Согласно Положению, "инофирма, помимо указанных сведений и документов, представляет по запросу соответствующего аккредитующего органа другие сведения и документы, касаюшиеся ее деятельности (информацию об уставном капитале инофирмы, рекомендательное письмо банка, услугами которого фирма пользуется, и т.д.)".

В качестве иллюстрации приведен "Список документов, необходимых для открытия представительства иностранного банка в России (г. Москва)". В Щентральный банк Российской Федерации (ЦБ РФ) представляются:

1. Официальное письмо-прошение на имя Председателя Центрального банка РФ с информацией о целях открытия представительства в Москве.

2. Устав банка, выписка из банковского реестра или разрешение на осуществление банковской деятельности в оригинале и нотариальных копиях, заверенных в установленном порядке консульскими учреждениями Российской Федерации за границей, в переводе на русский язык (включая письмо-прошение).

3. В случае, если по законодательству страны местопребывания банка для открытия представительства требуется разрешение, то необходимо представить это разрешение.

4. Лицо, ведущее переговоры по вопросу аккредитации представительства банка, должно иметь рекомендательное письмо банка или доверенность банка, заверенную в установленном порядке консульским отделом Российской Федерации за границей.

5. Биографическая справка на главу представительства и его заместителя (один экземпляр на языке страны местопребывания банка и два экземпляра перевода на русский язык).

6. Рекомендательные письма российских организаций, информация об уже имеющихся деловых связях банка на территории СНГ, а также о перспективах развития этих связей.

7. Последний годовой отчет банка. 
8. Информация о структуре руководящих органов банка.

9. Дата и место разрешения и регистрации банковского устава.

10. Справка УПДК или другой организации о возможности размещения офиса по адресу, ссылка на договор об аренде.

11. Краткая справка о банке (1-1,5 страницы).

12. Копия платежного поручения о переводе денег за аккредитацию.

Все документы должны быть представлены в двух экземплярах.

К существу содержания документов, подаваемых для получения аккредитации, также предъявляются различные требования. Они проявляются в методике и глубине проверки надежности и деловой репутации фирмы.

В связи с аккредитацией представляются уместными следующие соображения. Во-первых, при аккредитации желательно, чтобы переговоры об открытии представительства вел иностранный сотрудник самой фирмы. Если инофирму будет представлять российский гражданин, могут возникнуть некоторые затруднения (например, в случае необходимости уточнить конкретные факты, касающиеся деятельности инофирмы, он может не располагать какой-то информащией. Понадобится время для уточнений, эапросов, а все это требует дополнительного времени). Во-вторых, сотрудники аккредитуюших органов, как правило, с большим вниманием и пониманием относятся $\kappa$ иностранным гражданам. В-третьих, с учетом особого места представительств иностранных банков более строгим является контроль за их регистрацией и деятельностю.

Заметим, что имеют место отказы в аккредитации. Так, одной иностранной фирме Торгово-промышленная палата РФ (ТПП РФ) отказала в аккредитащии из-за ее неустойчивого финансового положения.

Министерство внешнеэкономических связей РФ (МВЭС РФ) также неоднократно отказывало в выдаче разрешения на открытие представитељства. При вынесении решения МВЭС руководствуется следующими принципами: соответствует ли характер деятельности фирмы профилю МВЭС, каков опыт работы на российском рынке у данной фирмы, насколько известна фирма на мировом рынке. Необходимо отметить, что если раньше существовала так называемая "планка" (величина ежегодного торгового оборота фирмы), то теперь ее нет, и теоретически любая мелкая фирма может быть аккредитована при MBЭС.

После прохождения аккредитации выдается разрешение на открытие представительства на территории РФ, на основании которого можно открыть представительство теоретически в любой точке России. На практике же действуют ограничения, установленные от- 
дельными нормативными актами. Так, согласно статье 6 Указа Президента РФ от 26 декабря 1991 г. № 318 "Об условиях экономического эксперимента по созданию особого порядка инвестирования на территории Республики Карелия", Совету Министров Республики Карелия предоставлено право выдавать разрешения на открытие на территории Карелия представительств иностранных фирм при условии ограничения пространства их деятельности территорией Республики Карелия. Поэтому вполне возможно, что местные органы будут требовать от инофирмы еще одну аккредитацию.

На сегодняшний день в соответствии с положениями о свободных экономических зонах, утвержденными постановлениями Совета Министров РФ и распоряжениями Председателя ВС РФ, такая же ситуация имеет место в Санкт-Петербурге, Выборге, в Кемеровской, Новгородской и некоторых других областях России.

\section{Регистрация в местных органах власти}

Необходимо ли регистрироваться представительству иностранного юридического лица?

В действующем законодательстве прямо не говорится о необходимости регистрации представительств иностранных юридических лиц. Федеральные органы еще не урегулировали порядок их регистрации. Следовательно, пока регистрация для представительств иностранных юридических лиц не является обязательной. Вместе с тем каждое представительство осуществляет деятельность в определенном районе. В силу этого многие представительства иностранных юридических лиц по требованию московских властей проходят регистрацию, размер которой составляет 2000 руб. и 2,5 минимальньіх зарплаты.

На практике установились следующие три вида регистращи:

1. Регистрация в филиале Московской регистрационной палаты (МРП), где уже разработан и действует Порядок регистрации представительств ИЮЛ (пока не утвержденный).

2. Регистрация через членство Московской торгово-промышленной палаты (МТПП), причем регистрация будет произведена в том же филиале МРП, а ежегодный членский взнос составит 7500 долл.

Во исполнение распоряжения мэра № 54-PM МТПП разработала Временное положение "О деятельности расположенных в г. Москве представительств (филиалов, агентств) иностранных юридических лиц, а также иностранных физических лиц, ведущих предпринимательскую деятельность в г. Москве" (далее - Временное положение). Чрезвычайно трудно определить, кем и когда оно принято и является ли оно обязательным предписанием или рекомендацией. Важно 
отметить, что действие Временного положения распространяется на все существующие представительства, так как оно различает две категории - "фактически действующее представительство" (п. 2.12) и "вновь открываемое представительство" (п. 2.13).

Согласно распоряжению, 50\% ежегодного членского взноса предназначается для развития Москвы. Остальные 50\%, согласно письму МТII, адресованному всем представительствам в Москве, и в соответствич с разъяснениями, данными сотрудниками МТПП, идут на аккредитацию, регистрацию, постановку на учет в различные органы и пољьзование различными правами. Таким образом, зарегистрировавшись в соответствии с этим Положеннем, представительство становится обладателем "права на приобретение, аренду или передапу в пользование имущества и имущественных прав, относимых к муниципальной собственности и/или полному хозяйственному ведению органов управления г. Москвы, муниципальных предприятий и организаций" (п. 2.3). Представителства получают также право размещать в Москве наружную рекламу и могут стать обладателями иных прав "по усмотрению правительства г. Москвы" (п. 2.3). Положением предусматривается ежегопное платное продление регистрации и аккредитации. Мы не смогли выяснить юридический смысл этого действия.

Хотя, по информации заместителя директора МТПП Константина Константиновича Полищука, ее членами стали уже 30 представительтв, мы не смогли выявить таковые. По результатам проведенного нами опроса* представительства фирм "Ай-Би-Эм корп." (IBM), "Байер AГ" ("Вауеr AG"), "Америкэн экспресс К"” ("American Express Co."), "Дженерал электрик К" ("General Electric Co."), "Зименс AГ" ("Siemens AG") и других не являются членами МТПП.

3. Регистрация за пределами Москвы. Стоимость ее - 2000 руб. Этот вариант на практике наиболее удачный.

Если представительство не зарегистрировалось, то в силу отсутствия законодательста по данному вопросу претензии к нему не могут бытъ предъявлены.

\section{Постановка на учет в Налоговой инспекиия}

Нужно ли становиться на учет в Налоговой инспекции? Да, это необходимо.

Во-первых, это прямо предусмотрено действующей инструкцией Министерства финансов СССР от 26 февраля 1991 г. N 18 "О порядке

* Опрос был проведен 17-18 ноября 1993 г. 
учета плательшиков налогов и других обязательных платежей в бюджет".

Во-вторых, без этого условия банки не открывают счета.

Постановка на учет в Налоговой инспекции производится бесплатно в Управлении налогообложения иностранных юридических и физических лиц Налоговой инспекции Москвы. От представительства при этом требуется единственный документ - разрешение на открытие представительства.

Согласно разделу II инструкции государственной Налоговой службы РФ от 14 мая 1993 г. № 20 "О налогообложении прибыли и доходов иностранных юридических лиц", "под постоянным представительством иностранного юридического лица в Российской Федерации для целей налогообложения понимаются бюро, контора, агентство, любое другое постоянное место регулярного осуществления деятельности... по извлечению дохода на территории Российской Федерации или за границей, а также любые организации и физические лица, уполномоченные иностранными юридическими лицами осуществлять представительские функции в Российской Федерации" (п. 6).

Практически это означает, что для Налоговой инспекции существует еще одна организационно-правовая форма предпринимательской деятельности - иностранное юридическое лицо, ведущее коммерческую деятельность на территории РФ через представительство. Это приводит к тому, что некоторые представительства действительно являются только представительствами, а другие кроме или вместо своих основных функций осуществляют еще и коммерческую деятельность и вносят налоги в Налоговую инспекцию.

\section{Постановка на учет в Пенсионном фонде}

Сегодня, когда любое представительство имеет право самостоятельно нанимать персонал из числа граждан страны пребывания, все большее число фирм пользуется этим правом. Глава представительства или ИЮЛ, которое он представляет, становится работодателем.

В соответствии с постановлением Верховного Совета РФ от 27 декабря 1991 г. № 2122-1 "Вопросы Пенсионного фонда Российской Федерации (России)" работодатель обязан встать на учет в Пенсионный фонд.

* Настоящая информация о Пенсионном фонде предоставлена специально для данной публикации Главным уполномоченным Пенсионного фонда Российской Федерации по работе с иностранными представительствами Б.А. Косаревым. 
Для большинства представительств весьма важна их репутация, слагаемым которой является отношение фирмы к своим служащим. Если представительство не будет состоять на учете в ПФ, его служащим не будет установлена государственная пенсия. Имеют место случаи обращения иностранных граждан, работающих в посольствах в Москве, с просьбой оформить пенсию в России, что допускается законодательством РФ. Это обстоятельство тоже нужно учитывать представительствам в своей деятељьности.

Кроме того, установлено, что банки не имеют права открывать представительствам счет, пока им не будут представлены документы, подтверждающие постановку на учет в ПФ.

Постановка на учет производится бесплатно Группой по работе с иностранными представительствами Московского отделения Пенсионного фонда $Р \Phi$.

\section{Постановка на учет в Фонде обязатељього медицинского страхования}

Согласно "Инструкции о порядке взимания и учета страховых взносов (платежей) на обязательное медицинское страхование", утвержденной Постановлением Совета Министров РФ от 11 октября 1993 г. № 1018, представительство, нанявшее российских граждан, становится страховщиком и обязано встать на учет в Фонде обязательного медицинского страхования (OMC).

По этой инструкции банки также не имеют права открывать представительству счет, пока не получат подтверждения о постановке на учет в указанном фонде.

\section{Oткрытие счета в бапке}

Напомним прежде всего, что иностранные юридические лица в России являются нерезидентами.

Возможность открытия рублевого счета для представительтв нерезидентов определяется "Инструкцией Центрального банка Российской Федерашии (Банк России)" от 16 июля 1993 г. № 16 (далее - Инструкция). Согласно пункту 4 раздела Инструкции, "находящиеся на территории Российской Федерации представительства и филиалы нерезидентов (за исключением иностранных дипломатических, торговых и иных официальных представительств) не могут открывать

* Незначительные изменения Инструкции внесены телеграммами № 48 и 49 ЦБ РФ в 1993 году. 
рублевые счета на свое имя в уполномоченных банках Российской Федерации.

Иностранные дипломатические, торговые и иные офишиальные представительства заключают договор банковского счета с уполномоченными банками Российской Федерации от своего имени. Иные представительства, а также филиалы нерезидентов заключают договор банковского счета от имени и по поручению своих учредителей. При зтом права и обязанности по договору возникают у нерезидентов - учредителей представительств, филиалов".

Согласно Инструкции, представительтва могут иметь два вида таких счетов: "T" - текущий и "И" - инвестищионный. На практике жесткие ограничения, наложенные ЦБ РФ на операчии по этим счетам, привели К тому, что эта Инструкция не применяется. Счет открывается лишь для того, чтобы оплачивать расходы представительства. Для открытия счета представительство должно представить десять документов.

पтобы открыть валютный счет, от представительства требуются те же самые документы, поскольку спешиальной инструкции о порядке открытия и ведения валютных счетов иностранных юридических лиц в РФ не существует. Формально действующая Инструкция Госбанка СССР не применяется.

2. IРОДЛЕНИЕ АКСКРЕДИТАИИИ И СРОКА ПЕЯТЕЛЬНОСТИ ПРВДСТАВНTEЛЬCTBA,

Продление аккредитации предусмотрено Положением 1989 года: "Представительства инофирм открываются... с возможностью последующего продления срока деятељьости представительства в СССР в случае заблаговременного обращения инофирм в аккредитующий орган, если цель представительтва выполнена не полностью и будет признано целесообразным такое продление".

На наш взгляд, понятие "продление срока деятельости представительства" и сама процедура продления юридически бессмысленны. Разрешение - документ, дающий право на открытие, то есть административный акт однократного действия. При так называемом "продлении" выдается точно такое же разрешение на открытие представительтва, то есть как бы снова разрешается то, что уже было разрешено. На практике все подчиняются этому требованию.

Торгово-промышленная палата РФ взимает сбор за продление. Эти сборы позволяют ей предоставлять массу услуг аккредитованным при ней представительствам, например давать бизнес-информацию о потенциальных партнерах в РФ, экспортных возможностях 
российских предприятий, рассылать свои периодические издания. Каждые три месяца в конгресс-центре ТПП проводится встреча всех представитељств и представителей заинтересованных министерств и ведомств, где обсуждаются возникшие проблемы, проводятся встречи с приглашенными специалистами и т.д. ТПП РФ поддерживает постоянную связь с региональными ТПП и при открытии фирмой представитељств в регионах России оказывает ей содействие через местные палаты.

\section{3. ЗАКРЫТИЕ ПРЕДСТАВИТЕЛЬСТВА}

Действующее законодательство содержит на этот счет конкретные указания. Согласно Положению 1989 года, "деятельность представительства инофирмы в СССР прекращается:

a) по истечении срока, на который выдано разрешение, и если фирма не обратилась с просьбой о продлении срока деятельности представительства;

б) в случае ликвидации инофирмы, имеющей представительство B CCCP;

в) в случае прекращения действия заключенного СССР с иностранным государством межправительственного соглашения, на основании которого открыто представительство, если это прямо предусмотрено положениями такого соглашения;

г) по решению соответствующего аккредитующего органа в случае нарушения представительстом условий, на которых инофирме разрешены его открытие и деятельность, или нарушения советского законодательства;

д) по решению инофирмы, открывшей представительство".

Известны случаи закрытия представительств по решению аккредитующих органов. Так, в 1992 году ЦБ РФ было отозвано разрешение на аккредитацию у представитељьтва одного из финансово-кредитных учреждений за ведение коммерческой деятельности, признанной несовместимой со статусом представительства.

\section{4. ПРОБЕЛЫ В ЗАКОНОДАТЕЛЬСТВЕ}

Ознакомившись со всеми актами, регулируюшими данную область отношений, пройдя неоднократно все этапы аккредитации и регистращии, мы сочли необходимым проверить всю полученную информаџию еще раз.

В результате оказалось, что сложилась некая цепочка по исполнению распоряжения мэра. Элемент № 1 - Московская мэрия, кото- 
рая намерена принять соответствующее Положение. Элемент № 2 МТПП, разработавшая проект Положения и установившая сумму членского взноса. Элемент № 3 - представительство иностранной фирмы, которая доводит информацию об уплате взноса до иностранных представительств.

Вследствие отсутствия специального законодательства взаимоотношения элементов $\mathfrak{N}^{0} 1,2,3$ не урегулированы надлежащим образом.

Каково же положение с законодательством в этой области?

В беседе с нами 23 ноября 1993 г. начальник отдела Московской мэрии по маркетингу и экономической безопасности Валерий Дмитриевич Иванов (ответственный за рассмотрение Положения) сообщил, что Временное положение о деятельности представительст инофирм было представлено на рассмотрение в правительство в сентябре 1993 года. Оно было отправлено на доработку. Положение пока не принято. По мнению В.Д. Иванова, членство в МТПП должно быть добровольным.

К.К. Полищук (МТПП) 10 ноября 1993 г. сообщил нам, что разработано Постоянное положение, которое находится на рассмотрении соответствующих органов, и ознакомил с письмом МТПП представитељьство фирмы "Ментор информатик", в котором и указана сумма членского взноса.

Преимущество правового положения представительства ИЮЛ в сравнении с правовым положением предприятия с иностранными инвестициями (ПИИ) состоит в том, что фактически представительство является субъектом федерального уровня. В противоположность ему ПИИ - субъект правоотношений с местными органами власти. Если местные власти могут ввести дополнительный налог на деятельность ПИИ или предпринять какие-либо действия, затрагиваюшие интересы ПИИ, вплоть до прекращения его деятельности, то с представительтвом такое возможно лишь после получения соответствующих полномочий от федеральных властей. Но это уже является предметом межгосударственных отношений.

В настоящее время разрабатываются проекты новых документов, регламентируюших деятельность иностранных представительств в РФ. Это - "Положение о порядке открытия и деятельности в РФ представительств иностранных фирм, банков и организаций" и инструкция Государственной налоговой службы "О налогообложении прибыли и доходов иностранных юридических лиц". Хочется надеяться, что специалисты учтут при их разработке упомянутые выше противоречия и пробелы в законодательстве.

Автор выражает искреннюю благодарность представителям ряда учреждений (МВЭС, ЦБ РФ, ТПП РФ, Государственной налоговой инспекции) за существенную помощь в подготовке зтой статьи. 